\title{
Comparison between Listeria monocytogenes single and multipathogen detection methods
}

\author{
Comparação entre os métodos de detecção de Listeria monocytogenes simples e \\ multipatógenos
}

\author{
Vanessa Rodrigues de Souza ${ }^{1}$; Vinicius Lins Ferreira ${ }^{1}$; Harli Pasquini-Netto ${ }^{1}$, Fernanda Stumpf Tonin ${ }^{1}$; \\ Wanda Moscalewski Abrahão ${ }^{1}$; Roberto Pontarolo ${ }^{1}$ \\ ${ }^{1}$ Departmento de Farmácia, Programa de Pós Graduação em Ciências Farmacêuticas, Universidade Federal do Paraná, \\ Curitiba, Brazil
}

Av. Prof. Lothario Meissner 632, 5541 3360-4076

Email:vanessard@outlook.com

\begin{abstract}
*This project is supported by the grant 40001016042P8 2015-2016, from CAPES and part of MSc Program in Pharmaceutical Sciences from Federal University of Paraná
\end{abstract}

*Este projeto foi apoiado pela bolsa 40001016042P8 2015-2015, da CAPES e parte do MSc no Programa de Ciências Farmacêticas da Universidade Federal do Paraná

\begin{abstract}
Multipathogen detection methods have been used to provide a broad range of microorganism detection. We aimed to identify the most searched pathogens in L. monocytogenes detection methods and evaluate if there are sensitivity and specificity differences between single and multipathogen methods. A systematic review was performed by including studies carried out in order to detect L. monocytogenes in a broad range of food sample. A total of 2770 records were retrieved, of which 191 were selected. The majority of the studies (104) presented multipathogen detection, other 87 searched for L. monocytogenes specifically. From the studies for multipathogen detection; other Listeria species (19.4\%), Salmonella spp. (21.6\%), E. coli O157:H7 (13.2\%), Staphylococcus spp. (9.7\%), E. coli $(5.7 \%)$ were more frequently reported. Sensitivity and specificity calculations were derived from only 26 studies, because they compared their data with an official method. Sensitivity and specificity values were close to $100 \%$, showing that others characteristics such as time and cost should be considered to evaluate alternative methods in further research. As a conclusion, evidence generated regarding L. monocytogenes identification methods contribute to method improvements and listeriosis control.
\end{abstract}

Keywords: L. monocytogenes, methods, pathogens, sensitivity, specificity.

\section{Resumo}

Os métodos de detecção para múltiplos patógenos têm sido usados para fornecer uma ampla faixa de detecção de microrganismos. Objetivou-se identificar os patógenos mais buscados nos métodos de detecção para L. monocytogenes e avaliar se existem diferenças nas taxas de sensibilidade e especificidade entre os métodos que buscaram identificar somente L. monocytogenes e os para múltiplos patógenos. Uma revisão sistemática foi realizada incluindo estudos desenvolvidos para detectar L. monocytogenes em amostras alimentares. Um total de 2770 registros foram recuperados, e destes 191 foram selecionados. A maioria dos estudos (104) apresentaram detecção de múltiplos patógenos, outros 87 buscaram L. monocytogenes especificamente. Dos estudos para a detecção múltipla; outras espécies de Listeria (19.4\%), Salmonella spp. (21.6\%), E. coli O157:H7 (13.2\%), Staphylococcus spp. (9.7\%), E. coli (5.7\%) foram mais frequentemente reportadas. Os cálculos de sensibilidade e especificidade foram derivados somente de 26 estudos, pelo fato de compararem seus resultados com um método oficial. As taxas de sensibilidade e especificidade foram próximas a $100 \%$, demostrando que outras características como tempo de análise e custo devem ser consideradas para avaliar métodos alternativos em pesquisas futuras. Em conclusão, evidencias geradas sobre os métodos de identificação de L. monocytogenes, contribuem para melhoria dos métodos e controle da listeriose.

Palavras-chave: especificidade, L. monocytogenes, metodos, patógenos, sensibilidade. 


\section{Introduction}

The detection and monitoring of foodborne pathogens by food industries and food safety authorities facilitate outbreak prevention ${ }^{[1]}$. Over $25 \%$ of food productions worldwide are lost every year due to food contaminations ${ }^{[2]}$. Listeria monocytogenes is an important bacterium that causes listeriosis, a foodborne disease with high mortality rates (20-30\%) that affects mainly immunocompromised patients ${ }^{[3]}$. Since $L$. monocytogenes can grow in several food groups, the early detection and control of this pathogen are essential to prevent further health-related issues ${ }^{[4]}$. Considering these concerns, the improvement of microbiological laboratory analyses is always required to ensure product quality and safety ${ }^{[5]}$, even more due to the fact that the standard approved assays for microorganism detection are laborious and time-consuming ${ }^{[6,7]}$.

The standard L. monocytogenes identification methods in food samples are based on an enrichment phase using liquid culture media. After, differential plating in solid media is performed in order to obtain isolated colonies for biochemical and serological identification ${ }^{[8]}$. These methods are described by recognized organizations such as: United States Food and Drug Administration (FDA), Association of Official Analytical Chemists (AOAC), International Organization for Standardization (ISO) and United States Department of Agriculture/Food Safety and Inspection Service (USDA/FSIS) [9].

The use of alternative methods especially multipathogen detection tools is increasingly convenient since it enables the detection of more than one microorganism simultaneously, with the advantage of using few materials and quickly delivering results ${ }^{[10]}$. These multiple detection methods are already reported in the literature for hygiene indicators and important human pathogens as well ${ }^{[11]}$. However, the simultaneous detection of microorganisms may introduce bias and mask the presence of the target pathogen or even reducing methods specificity and sensitivity.

Thus, we aimed to perform a systematic review and statistical analysis to compare single detection methods of Listeria monocytogenes with multiplex detection methods in food samples.

\section{Introdução}

A detecção e monitoramento dos patógenos alimentares por parte das indústrias alimentícias e autoridades de segurança alimentar facilitam a prevenção de surtos [1]. Mais de $25 \%$ das produções alimentares em todo o mundo são perdidas todos os anos devido a contaminação alimentar ${ }^{[2]}$. Listeria monocytogenes é uma importante bactéria que causa a listeriose, uma doença com altas taxas de mortalidade (20-30\%) que afeta principalmente pacientes imunocomprometidos ${ }^{[3]}$.

Uma vez que L. monocytogenes pode crescer em vários grupos de alimentos, a pronta detecção e o controle desse patógeno são essenciais para prevenir outros problemas relacionados à saúde ${ }^{[4]}$. Em virtude destas preocupações, a melhoria das analises laboratoriais microbiológicas se faz necessária para garantir a qualidade e segurança dos produtos ${ }^{[5]}$, agravado pelo fato que os ensaios oficiais para a detecção de microrganismos são laboriosos e demorados ${ }^{[6,7]}$.

Os métodos oficiais de identificação de L. monocytogenes em alimentos são baseados na etapa de enriquecimento seletivo por meio do use de meios de cultura. Posteriormente, o plaqueamento diferencial é realizado em meios de cultura sólidos para a obtenção de colônias isoladas para a identificação bioquímica e sorológica ${ }^{[8]}$. Os métodos convencionais oficiais para o isolamento de L. monocytogenes em alimentos são os descritos por organizações renomadas como United States Food and Drug Administration (FDA), Association of Official Analytical Chemists (AOAC), International Organization for Standardization (ISO) e United States Department of Agriculture/Food Safety and Inspection Service (USDA/FSIS) ${ }^{[9]}$.O uso de métodos alternativos especialmente os de detecção de múltiplos patógenos é extremamente conveniente, já que permitem a detecção simultânea de microrganismos, com a vantagem de usar poucos materiais e entregar rapidamente os resultados ${ }^{[10]}$. Estes métodos de detecção múltipla já são reportados na literatura para a identificação de indicadores das condições de higiene, como também importantes patógenos humanos ${ }^{[11]}$. No entanto, a detecção simultânea de microrganismos pode introduzir viés e mascarar a presença de patógenos alvo, e até mesmo reduzir a sensibilidade e especificidade dos métodos.

Desta forma, nosso objetivo foi realizar uma revisão sistemática e análise estatística sobre a comparação de métodos de detecção simples para Listeria monocytogenes com aqueles de detecção para múltiplos patógenos alimentares. 


\section{Methods}

This study is part of a larger project which examines methods for L. monocytogenes detection, carried out in accordance to the Cochrane Collaboration and PRISMA (Preferred Reporting Items for Systematic Reviews and Meta-Analyses) recommendations ${ }^{[12,13]}$. All steps of the systematic review were conducted by two independent researchers. Discrepancies were conciliated in consensus meetings using a third author as a referee.

The systematic searches were conducted in MEDLINE (by PubMed), Scopus and Web of Science (by Isi of Knowledge) electronic databases. The following descriptors and their variants were used: "food"; "identification"; "detection"; "quantification"; "Listeria monocytogenes"; "L. monocytogenes"; "listeria infection"; "listeriosis", combined with the Boolean operators "AND" and "OR". The search strategy for Medline (by Pubmed) was food[Title/Abstract] OR "foodborn diseases"[Title/Abstract] OR aliment [Title/Abstract] OR "ready to eat"[Title/Abstract] AND identification[Title/Abstract] OR detection[Title/Abstract] OR quantification [Title/Abstract] OR "biochemical methods" OR "immunological methods"[Title/ Abstract] OR "molecular methods" OR spectrometry [Title/Abstract] OR chromatography[Title/ Abstract] OR "microbiological methods" OR "serological methods"[Title/Abstract] OR "phage typing" [Title/Abstract] OR electrophoresis[Title/Abstract] AND Listeria[Title/Abstract] OR "Listeria monocytogenes" OR "L. monocytogenes" [Title/Abstract] OR listeriosis[Title/Abstract] OR "Listeria infection" [Title/Abstract] OR Listeria[MeSH Terms] OR "Listeria monocytogenes"[MeSH Terms]. The search strategy for Scopus was food OR aliment OR "foodborn disease" AND identification OR spectrometry OR chromatography OR electrophoresis AND Listeria OR "Listeria monocytogenes" OR "L. monocytogenes" OR listeriosis OR "Listeria infection" (Filter: document type article). The search strategy for Web of Science (via Isi of Knowledge) was (TOPIC $=$ food OR "foodborn disease") AND (TOPIC $=$ spectrometry OR chromatography OR electrophoresis AND $($ TOPIC $=$ Listeria OR "Listeria monocytogenes" OR "L. monocytogenes" OR listeriosis OR "Listeria infection"). Additionally, a manual search was performed on grey literature.

We included papers published until August 2016 which reported data on detection methods (single or multiplex) developed for identification of $L$. monocytogenes in a broad range food samples, evaluating if there are sensitivity and specificity differences between them. Studies with focus on another aims (unless method

\section{Metodos}

Este trabalho é parte de um projeto maior que estuda os métodos de detecção de L. monocytogenes, conduzido de acordo com a Cochrane Collaboration e as recomendações PRISMA (Preferred Reporting Items for Systematic Reviews and Meta-Analyses) ${ }^{[12,13]}$. Todos os passos da revisão sistemática foram realizados por dois revisores independentes. Discordâncias foram conciliadas através de reuniões de consenso contando com um terceiro revisor para a decisão final.

A busca sistemática foi conduzida nas bases MEDLINE (via PubMed), Scopus e Web of Science (via Isi of Knowledge). Os seguintes descritores e suas variações foram usados: "food"; "identification"; "detection"; "quantification"; "Listeria monocytogenes"; "L. monocytogenes"; "listeria infection"; "listeriosis", combinados pelos operadores Boleanos "AND" e "OR". A estratégia de busca para o Medline (via Pubmed) foi food[Title/Abstract] OR "foodborn diseases"[Title/Abstract] OR aliment [Title/ Abstract] OR "ready to eat"[Title/Abstract] AND identification[Title/Abstract] OR detection[Title/Abstract] OR quantification [Title/Abstract] OR "biochemical methods" OR "immunological methods"[Title/ Abstract] OR "molecular methods" OR spectrometry [Title/Abstract] OR chromatography[Title/Abstract] OR "microbiological methods" OR "serological methods"[Title/Abstract] OR "phage typing" [Title/ Abstract] OR electrophoresis[Title/Abstract] AND Listeria[Title/Abstract] OR "Listeria monocytogenes" OR "L. monocytogenes" [Title/Abstract] OR listeriosis[Title/Abstract] OR "Listeria infection" [Title/Abstract] OR Listeria[MeSH Terms] OR "Listeria monocytogenes"[MeSH Terms]. A estratégia de busca para Scopus foi food OR aliment OR "foodborn disease" AND identification OR spectrometry OR chromatography OR electrophoresis AND Listeria OR "Listeria monocytogenes" OR "L. monocytogenes" OR listeriosis OR "Listeria infection" (Filtro: artigo como tipo de documento). A estratégia de busca pelo Web of Science (via Isi of Knowledge) foi (TOPIC= food OR "foodborn disease") AND (TOPIC = spectrometry OR chromatography OR electrophoresis AND $($ TOPIC $=$ Listeria OR "Listeria monocytogenes" OR "L. monocytogenes" OR listeriosis OR "Listeria infection"). Adicionalmente, uma busca manual foi realizada na literatura cinzenta.

Nós incluímos artigos publicados até Agosto de 2016 que reportaram dados sobre os métodos de detecção (simples ou múltipla) desenvolvidos para a identificação de L. monocytogenes em variados tipos de alimentos, avaliando se há diferenças na sensibilidade e 
development); different language than German, Spanish, French, English, Italian or Portuguese; non-Roman characters; non-L. monocytogenes, non-food matrix; study type but original articles (review and patents) and articles that did not presented the data clearly or presented in an incomplete way were excluded.

The publication year, location and methods characteristics (target, food sample type) were extracted from the selected studies. When there was comparison with the standard method, data from true positive (TP), true negative (TN), false positive (FP) and false negative (FN) were also extracted to enable sensitivity and specificity comparisons between multiplex method with those for only L. monocytogenes. Data were reconstructed in $2 \times 2$ tables which were used to calculate sensitivity and specificity. The analyses were carried out using Review Manager 5.3 software and reported as rates with $95 \%$ confidence interval $(95 \% \mathrm{CI})$.

\section{Results}

After exclusion of duplicates, a total of 2,770 studies were retrieved in the electronic database. During the screening of titles and abstracts, 2,213 studies were excluded, and 557 studies were evaluated by full-text reading. Finally, a total 191 studies were included in the synthesis, but only 26 allowed the sensitivity and specificity evaluations for present comparisons against standard methods (Figure 1).

We found 87 studies (published between 1996 and 2016) reporting Listeria monocytogenes single detection methods, of which $19.5 \%$ (17/87) included data that enabled sensitivity and specificity calculations. The overall results of sensitivity and specificity were respectively 0.98 (CI 95\%: 0.98-0.99) and 0.97 (CI 95\%: 0.96-0.98) (Figure 2). The studies were carried out primarily in Europe and in diverse food matrices. The most employed methods were molecular assays, such as Polymerase Chain Reaction (PCR). The genetic markers hly A (encods listeriolysin $\mathrm{O}$ ), ssr A (simple sequence repeat), act $\mathrm{A}$ (actin assembly-inducing protein), prf A (platelet rich fibrin), rRNA were reported as markers to distinguish $L$. monocytogenes from other bacterias (Table 1).

Considering the 191 studies, most (104/191) aimed to detect multiple pathogens. Different pathogens were cited for detection, searching other Listeria species especificidade entre os mesmos. Estudos com focos em outros objetivos (que não fosse o desenvolvimento de um método); em idioma a não ser alemão, espanhol, francês, inglês, italiano ou português; em caracteres não romanos, que não buscavam $L$. monocytogenes; não usavam matrizes alimentares; em tipo de estudo que não era artigo original (revisões e patentes) e artigos que não apresentaram os dados claramente ou apresentaram de maneira incompleta foram excluídos incompletos foram excluídos. $\mathrm{O}$ ano de publicação, local e características do método (alvos, tipo de amostra alimentar) foram extraídos dos estudos selecionados. Quando houve comparação com método oficial, dados de verdadeiro positivos (VP), verdadeiro negativo (VN), falso positivo (FP) e falso negativo (FN) foram extraídos para possibilitar a comparação entre a sensibilidade e especificidade dos métodos para multi patógenos com aqueles de detecção somente de $L$. monocytogenes. Os dados foram plotados em tabelas $2 \times 2$ a fim de calcular a sensibilidade e especificidade. As analises foram realizadas usando o software Review Manager 5.3 e reportadas como taxas em intervalo de confiança de $95 \%$.

\section{Resultados}

Após a remoção das duplicatas, um total de 2.770 estudos foram recuperados através da busca nas bases de dados. Durante a triagem de títulos e resumos 2.213 foram excluídos e 557 avaliados para a leitura na íntegra. Por fim, 191 estudos foram incluídos, porém apenas 26 permitiram avaliações de sensibilidade e especificidade por apresentarem comparações com métodos oficiais (Figura 1).

Foram encontrados 87 estudos (publicados entre 1996 e 2016) que reportaram método simples de detecção para L. monocytogenes, dos quais 19,5\% (17/87) forneceram dados que permitiram os cálculos de sensibilidade e especificidade. As taxas gerais de sensibilidade e especificidade foram respectivamente 0,98\% (CI 95\%: 0,98-0,99) e 0,97 (CI 95\%: 0,96-0,98) (Figure 2).

Os estudos foram conduzidos principalmente na $\mathrm{Eu}-$ ropa e para diversas matrizes alimentares. Os métodos moleculares foram os mais empregados, como os de Polimerase Chain Reaction (PCR). Os marcadores hly A (codificando para listeriolysin $\mathrm{O}$ ), ssr A (simple sequence repeat), Act A (actin assembly-inducing protein), Prf A (platelet rich fibrin), rRNA foram relatados como alvos para a detecção molecular (Tabela 1).

Considerando os 191 estudos, a maioria (104/191) objetivou detectar multiplos patógenos. Foram citadas diferentes detecções de patógenos, sendo pesquisadas 


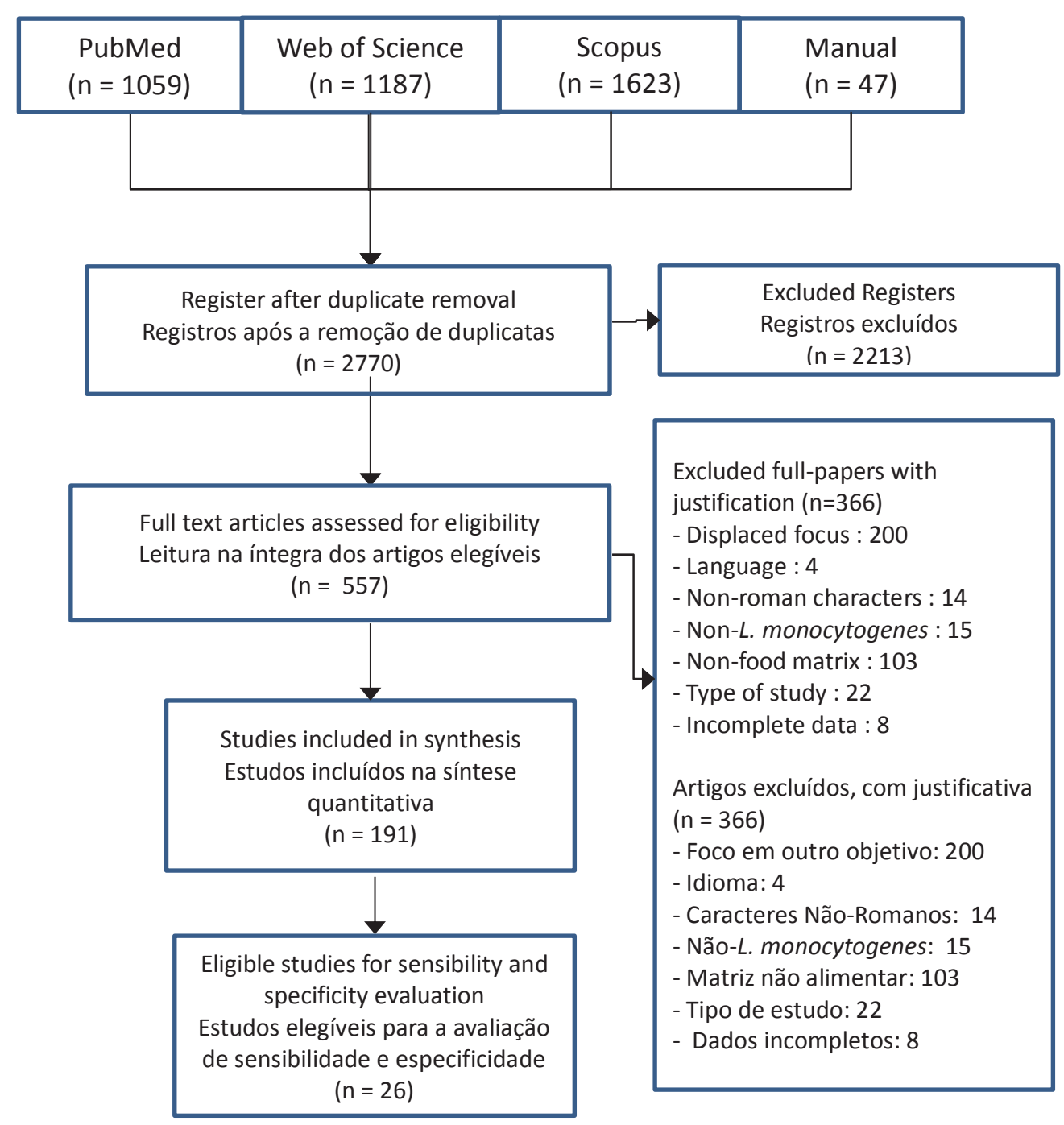

Figure 1/ Figura 1 - Prism Flowchart/Fluxograma Prisma 
Table 1/ Tabela 1 - Methods information / Informações dos métodos

\begin{tabular}{|c|c|c|c|c|c|}
\hline \multicolumn{6}{|c|}{ L. monocytogenes detection methods } \\
\hline \multicolumn{6}{|c|}{ Métodos de detecção de L. monocytogenes } \\
\hline Study & Country & Method & Target & \multirow{2}{*}{\multicolumn{2}{|c|}{$\begin{array}{l}\text { Food } \\
\text { Alimento }\end{array}$}} \\
\hline Estudo & País & Método & Alvo & & \\
\hline Cloke, 2016 & GB & PCR-RT (IAC) & - & \multicolumn{2}{|c|}{ Diverse (Diversos) } \\
\hline Curiale, 1994 & - & ELISA & - & \multicolumn{2}{|c|}{ Diverse (Diversos) } \\
\hline De Libato, 2001 & IT & PCR-EES (IAC) & - & \multicolumn{2}{|c|}{ Diverse (Diversos) } \\
\hline Duffy, 1999 & IE & PCR-AS & hly A & \multicolumn{2}{|c|}{ Meat (Cárneos) } \\
\hline Ingiani, 2007 & IT & DNA- hybr & - & \multicolumn{2}{|c|}{ Dairy/Meat (Lácteos/Cárneos) } \\
\hline Junge, 2006 & $\mathrm{DE}$ & PCR (IAC) & $\mathrm{mpl}$ & \multicolumn{2}{|c|}{ Diverse (Diversos) } \\
\hline Junge, 2012 & DE & PCR-RT & - & \multicolumn{2}{|c|}{ Diverse (Diversos) } \\
\hline $\begin{array}{l}\text { Kaclikova, } \\
2006\end{array}$ & SK & PCR & - & \multicolumn{2}{|c|}{ Diverse (Diversos) } \\
\hline Kretzer, 2007 & $\mathrm{CH}$ & CBD-MS & - & \multicolumn{2}{|c|}{ Dairy/Meat (Lácteos/Cárneos) } \\
\hline Loessner, 2007 & DE & Lux-Phage & - & \multicolumn{2}{|c|}{ Diverse (Diversos) } \\
\hline O`Grady, 2009 & IE & PCR (IAC) & ssr A & \multicolumn{2}{|c|}{ Diverse (Diversos) } \\
\hline Oravcová, 2007 & SK & PCR-RT & $\operatorname{act} \mathrm{A}$ & \multicolumn{2}{|c|}{ Diverse (Diversos) } \\
\hline $\begin{array}{l}\text { Rossmanith, } \\
2007\end{array}$ & AT & PCR (IAC) & $\operatorname{prf} \mathrm{A}$ & \multicolumn{2}{|c|}{ Diverse (Diversos) } \\
\hline Sthepan, 2003 & $\mathrm{CH}$ & VIT® & rRNA & \multicolumn{2}{|c|}{ Meat (Cárneos) } \\
\hline Tang, 2011 & - & LAMP & - & \multicolumn{2}{|c|}{ Meat (Cárneos) } \\
\hline Wan, 2003 & AU & PCR & - & \multicolumn{2}{|c|}{ Salmon (Salmão) } \\
\hline Wang, 2011 & $\mathrm{CN}$ & CPA & $\operatorname{lmo0733}$ & \multicolumn{2}{|c|}{ Meat (Cárneos) } \\
\hline \multicolumn{6}{|c|}{ Multiple detection methods } \\
\hline \multicolumn{6}{|c|}{ Métodos de detecção múltipla } \\
\hline Study & Country & Method & Pathogens & Target & Food \\
\hline Estudo & País & Método & Patógeno & Alvo & Alimento \\
\hline Badosa, 2009 & $\mathrm{ES}$ & PCR-RT (IAC) & $\mathrm{S}$ & hly $\mathrm{A}$ & $\begin{array}{l}\text { Fruit/Vegetables } \\
\text { (Frutas/Vegetais) }\end{array}$ \\
\hline Bansal, 1996 & $\mathrm{AU}$ & PCR & $\mathrm{L}$ & hly A & Dairy (Lácteos) \\
\hline Becker, 2005 & $\mathrm{DE}$ & PCR (BAX®) & $\mathrm{L}$ & - & $\begin{array}{l}\text { Smoked salmon } \\
\text { (Salmão } \\
\text { defumado) }\end{array}$ \\
\hline $\begin{array}{l}\text { Bernardi, } \\
2015.1\end{array}$ & $\mathrm{BR}$ & VIDAS.LMO2 & $\mathrm{L}$ & - & Dairy (Lácteos) \\
\hline $\begin{array}{l}\text { Bernardi, } \\
2015.2\end{array}$ & BR & VIDAS.LDUO.LMO & $\mathrm{L}$ & - & Dairy (Lácteos) \\
\hline Herman, 1995 & $\mathrm{BE}$ & $\mathrm{mPCR}$ & $\mathrm{L}$ & iap & Dairy (Lácteos) \\
\hline $\begin{array}{l}\text { Kawasaki, } \\
2009\end{array}$ & - & mPCR & $E, S$ & hly A & $\begin{array}{l}\text { Frozen food } \\
\text { (Comida } \\
\text { congelada) }\end{array}$ \\
\hline $\begin{array}{l}\text { Ruiz-Rueda, } \\
2011\end{array}$ & ES & mPCR-RT (IAC) & $\mathrm{S}$ & hly A & $\begin{array}{l}\begin{array}{l}\text { Diverse } \\
\text { (Diversos) }\end{array} \\
\end{array}$ \\
\hline Somer, 2003 & IL & PCR & $\mathrm{L}$ & Seq & $\begin{array}{l}\text { Ready-to-eat } \\
\text { (Prontos para o } \\
\text { consumo) }\end{array}$ \\
\hline $\begin{array}{l}\text { Vongkamjan, } \\
2016\end{array}$ & TH & MDA-LM & $\mathrm{L}$ & $\begin{array}{l}\text { hly A, sig } \\
\text { B }\end{array}$ & $\begin{array}{l}\text { Ready-to-eat } \\
\text { (pronto para o } \\
\text { consumo) }\end{array}$ \\
\hline
\end{tabular}

$\mathrm{S}=$ Salmonella spp.; $\mathrm{L}=$ Listeria spp.; $\mathrm{E}=$ E. coli $\mathrm{O} 157: \mathrm{H} 7$.

(19.4\%), Salmonella spp. (21.6\%), E. coli O157:H7 (13.2\%), Staphylococcus spp. (9.7\%) and, other E. coli (5.7\%) were reported in addition to L. monocytogenes (Figure 3). Other bacterias were less frequently reported: Shigela spp., Campylobacter spp., Enterococcus spp., Yersinia spp., Pseudomonas spp., Clostridiun spp., Vibrio spp., etc. The studies were published between1995 and 2016, nine of them (8.6\%) included results that enabled sensitivity and specificity calcula- outras espécies de Listeria (19,4\%), Salmonella spp. (21,6\%), E. coli O157:H7 (13,2\%), Staphylococcus spp. $(9,7 \%)$ e E. coli $(5,7 \%)$ foram reportados além de L. monocytogenes (Figura 3). Otras bacterias foram menos frequentemente reportadas: Shigela spp., Campylobacter spp., Enterococcus spp., Yersinia spp., Pseudomonas spp., Clostridiun spp. etc . Estes estudos foram publicados entre 1.995 e 2.016 , nove dos mesmos $(8,6 \%)$ revelaram resultados que possibilitaram 
tions. The overall results of sensitivity and specificity were respectively 0.96 (CI 95\%: 0.92-0.99) and 0.99 (CI 95\%: 0.99-1.00) (Figure 2). The studies were carried out in different countries and for a broad range of food matrices. The most employed methods were molecular assays, such as PCR. Hly A was the most mentioned marker among the studies. os cálculos da sensibilidade e especificidade. As taxas gerais de sensibilidade e especificidade foram respectivamente $0,96 \%$ (CI 95\%: 0,92-0,99) e 0,99 (CI 95\%: 0,99-1,00) (Figure 2). Os estudos foram conduzidos em diferentes países e para diversas matrizes alimentares. Os métodos moleculares foram os mais empre-

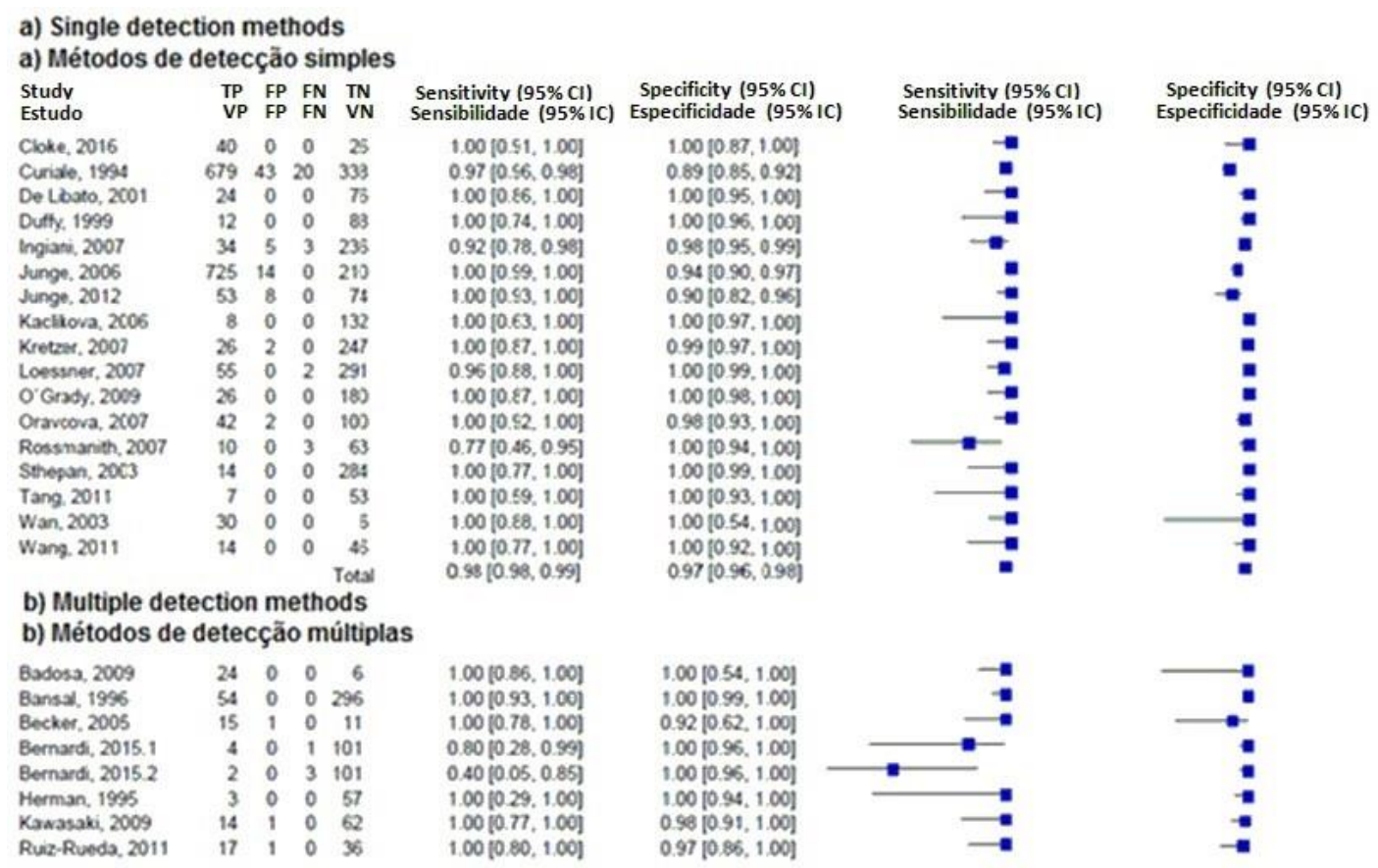

Figure 2/ Figura 2 - Sensitivity and Specificity for L. monocytogenes specific (a) and multi pathogen (b) detection method. / Sensibilidade e especificidade para métodos de detecção simples de L. monocytogenes (a) e multipla (b).

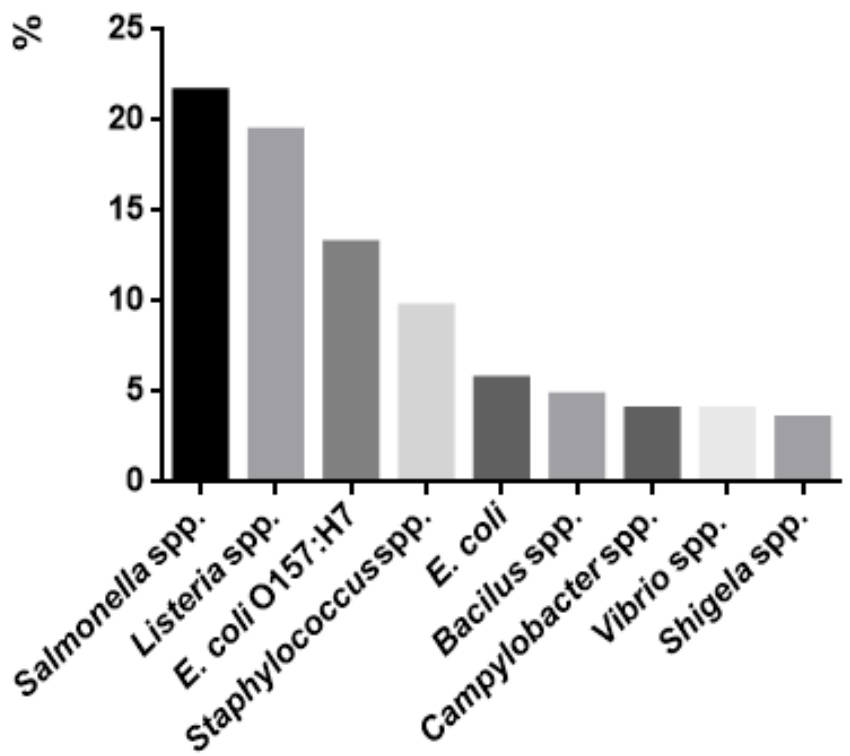

Figure 3/ Figura 3- Major pathogens searched for multiple detection methods / Principais patógenos buscados pelos métodos de detecção múltipla 


\section{Discussion}

This is the first systematic review to confront data on two sorts of microorganism identification methods (single and multiplex detections) as well to evaluate its sensitivity and specificity against official methods. Most of the evaluated studies presented multipathogen detection, which means that this methodology is increasingly used and is able to detect many foodborne pathogens at the same time. This is probably consequence of some of the advantages of this type of analyses, namely the consumption of fewer raw materials and the ability of cover a broad spectrum of potential pathogens ${ }^{[14,15]}$. This is important because it may permit the detection of a higher number of microorganisms simultaneously, foreseeing different foodborne diseases and ensuring product quality and safety.

Salmonella spp. was the most frequent studied pathogen followed by Listeria spp. Other microorganisms reported were E. coli O157:H7, E. coli, Bacilus spp., Campylobacter spp., Vibrio spp and Shigela spp due to the fact of some of them having the capacity to produce dangerous toxins ${ }^{[16]}$.

The most employed technique, in both simple and multiplex detection methods, was PCR. Most PCR methods have been based on the listeriolysin O gene (hly A) and other target genes located in the virulence cluster ${ }^{[17}$, ${ }^{18]}$. However, these genes are represented in single copies leading other molecular techniques targeting rRNA genes because they frequently appear in multiples copies in prokaryotes ${ }^{[19]}$. Unlike conventional techniques, PCR has also the capacity to accurately detect injured pathogen cells that have the potential to recover and grow when the food is consumed ${ }^{[20]}$.

Some PCR assays still need pre-enrichment procedures to ensure the detection of low numbers of viable pathogen cells ${ }^{[21]}$, but it is important to highlight that the analyses result delivery is considerably reduced when compared to classical identification methods (typically requires 96 hours to 216 hours versus 24 hours to 72 hours from PCR).

On the other hand, the alternatives methods have also some limitations. For instance, procedures like electrophoresis are considered time-consuming and tedious to detect amplified products by PCR. Regarding real-time PCR, the complication is based on cost and thermal cycling variations ${ }^{[18,22]}$. In addition, it is necessary to take care when conducting PCR assays due to the likelihood of contamination and the possibility to generate false positive results ${ }^{[23]}$. Also, some studies employed an intern amplification control (IAC) that is useful to discard gados, como PCR. O gene hly A foi o marcador mais mencionado entre os estudos.

\section{Discussão}

Esta é a primeira revisão sistemática para confrontar dados sobre dois tipos de métodos de identificação de microrganismos (detecções únicas e múltiplas) bem como avaliar a sua sensibilidade e especificidade em relação aos métodos oficiais. A maioria dos estudos avaliados apresentou detecção de multipatógenos, o que significa que esta metodologia é cada vez mais utilizada e é capaz de detectar muitos patógenos transmitidos pelo consumo de alimentos contaminados. Esta é provavelmente uma consequência de algumas das vantagens deste tipo de análise, nomeadamente o consumo de menos matéria-prima e a capacidade de cobrir um espectro mais amplo de potenciais agentes patogênicos ${ }^{[14,15]}$. Isto é importante porque pode garantir a detecção de um número mais elevado de microrganismos simultaneamente, prevendo diferentes doenças transmitidas por alimentos e garantindo a qualidade e segurança dos produtos.

Salmonella spp. foi o patógeno mais estudado seguido por Listeria spp. Outros microrganismos reportados foram E. coli O157:H7, E. coli, Bacilus spp., Campylobacter spp., Vibrio spp. e Shigela spp. devido a capacidade de alguns deles produzir perigosas toxina, podendo colocar em risco a saúde da população ${ }^{[16]}$.

A técnica predominantemente empregada tanto em métodos de detecção simples quanto em multiplex foi a de PCR. A maioria dos métodos de PCR baseia-se na detecção do gene listeriolisina $\mathrm{O}(H l y A)$ e outros genes alvo do cluster de virulência ${ }^{[17,18]}$. No entanto, estes genes são representados em cópias únicas fazendo com que outras técnicas moleculares, como as de alvo em genes de rRNA, sejam empregadas pelo fato de aparecem frequentemente em múltiplas cópias em procariontes ${ }^{[19]}$.

Ao contrário das técnicas convencionais, a PCR tem também a capacidade de detectar com precisão células patogênicas danificadas que têm potencial para se recuperar e crescer quando o alimento é consumido ${ }^{[20]}$.

Algumas técnicas de PCR ainda necessitam procedimentos para assegurar a detecção de um baixo número de células viáveis ${ }^{[21]}$, mas é importante ressaltar que o tempo pra entregar os resultados da análise é consideravelmente reduzido quando comparado aos métodos clássicos de identificação (geralmente levam de 96 horas a 216 horas contra 24 horas a 72 horas da PCR).

Por outro lado, os métodos alternativos também têm algumas limitações. Por exemplo, os procedimentos são 
false negative results, however, they raise the analysis costs ${ }^{[24]}$.

Few studies that employed the immunological methods were reported. According to previous studies, the great challenge of immunological assays is to eliminate antibody cross-reactivity that can hamper the analysis results ${ }^{[25]}$. Over recent years, other alternative methods with diverse principles such as chromatography and spectroscopy were developed, aiming to produce more robust results in less analysis time ${ }^{[26,27,28]}$. It seems evident that availability of fast and reliable detection methods is critical for microorganism identification, regardless if the method is for single or multiplex detection. However, our results have revealed that only few studies have properly compared the alternative method parameters against standard approved methods.

From the studies that enabled the sensibility and specificity calculations, rates of approximately $100 \%$ were obtained, even when searching multiple pathogens.

\section{Conclusion}

In conclusion, L. monocytogenes multipathogens detection methods presented high sensitivity and specificity rates, being advantageous alternatives in terms of time and financial savings. Given this type of diversity of detection methods in the Food Microbiology field, the selection of a method should consider various aspects (cost, time of analysis, acceptance of the method by official agencies and the scientific community, simplicity of operation, training, and the analyst qualifications, availability of reagents, culture media and other supplies) for further validation. Therefore, it is necessary to generate evidence that contributes toward an alternative method selection.

\section{Acknowledgement}

CAPES- Brazil. considerados trabalhosos como a eletroforese para detectar produtos de amplificação por PCR. Em relação à PCR em tempo real, a complicação é baseada em custo e variações dos termocicladores ${ }^{[18,22]}$. Além disso, para a realização de ensaios de PCR, é necessário ser cuidadoso devido à probabilidade de contaminação e à possibilidade de gerar resultado falso positivo ${ }^{[23]}$. Além disso, alguns estudos empregaram um controle interno de amplificação (IAC) que é útil para descartar resultado falso negativo, porém aumentam-se os custos de análise ${ }^{[24]}$. Poucos estudos empregaram os métodos imunológicos. De acordo com a literatura, o grande desafio dos ensaios imunológicos é eliminar a formação de ligações cruzadas que podem dificultar a interpretação do resultado das análises ${ }^{[25]}$. Nos últimos anos, desenvolveram-se outros métodos alternativos com diversos princípios, como cromatografia e espectroscopia, com o objetivo de produzir resultados mais robustos em menos tempo de análise ${ }^{[26,27,28]}$. Parece evidente que a disponibilidade de métodos de detecção rápidos e fiáveis é fundamental para a identificação de microrganismos, independentemente se o método é para detecção única ou multiplex. Entretanto, nossos resultados revelaram que somente alguns estudos contrastaram seus resultados com os métodos oficiais. Dos estudos em que foi possível obter os dados de sensibilidade e especificidade, obtiveram-se taxas gerais em torno de $100 \%$, mesmo quando a pesquisa era para múltiplos patógenos.

\section{Conclusão}

Conclui-se que os métodos de deteç̧ão de L. monocytogenes para múltiplos patógenos apresentaram alta sensibilidade e especificidade, sendo alternativas vantajosas em relação à economia de tempo e recurso financeiros. Dada a grande diversidade de tipos de métodos em Microbiologia de Alimentos, a seleção de um método deve considerar diversos parâmetros (custo, tempo de análise, aceitação do método por agências oficiais e comunidade científica, simplicidade de operação, treinamento e qualificações do analista, disponibilidade de reagentes, meios de cultura e outros suprimentos) para a posterior validação. Deste modo, ressalta-se a necessidade de geração de evidências que contribuam com a escolha de métodos alternativos microbiológicos.

\section{Agradecimentos}

CAPES- Brasil.

\section{Conflict of interests}


No conflicts of interest have been declared.

\section{Conflito de interesses}

\author{
Não há conflitos de interesse
}

\section{References/ Referências}

1. Delibato E, Gattuso A, Minucci A, Auricchio B, De Medici D, Toti L, et al. PCR experion automated electrophoresis system to detect Listeria monocytogenes in foods. J Sep Sci. 2009;32:3817-21.

2. Sarhan WA, Azzazy HM. Phage approved in food, why not as a therapeutic? Expert Rev Anti Infect Ther 2015;13:91-101.

3. Siegman-Igra Y, Levin R, Weinberger M, Golan Y, Schwartz D, Samra Z, et al. Listeria monocytogenes infection in Israel and review of cases worldwide. Emerging infectious diseases. 2002;8(3):305-10.

4. Kim H, Bhunia AK. SEL, a Selective Enrichment Broth for Simultaneous Growth of Salmonella enterica, Escherichia coli O157:H7, and Listeria monocytogenes. Applied and Environmental Microbiology. 2008;74(15):4853-66.

5. Auvolat A, Besse NG. The challenge of enumerating Listeria monocytogenes in food. Food Microbiology. 2016;53, Part B:135-49.

6. Bernardi GAW, Benetti TM, de Souza VR, de Francisco TG, Pontarolo R. Evaluation of the Detection Methods used for Investigation of Listeria and Listeria monocytogenes. Journal of Food and Nutritional Disorders. 2015; 4:1-4.

7. Nyachuba DG, Donnelly CW. Comparison of 3M Petrifilm environmental Listeria plates against standard enrichment methods for the detection of Listeria monocytogenes of epidemiological significance from environmental surfaces. Journal of food science. 2007;72(9):M346-54.

8. Silva, NJV, Silveira NFA, Taniwaki NH, Santos RFS, Gomes RAR. Manual de métodos de análise microbiológica de alimentos e água. 4 ed. São Paulo (SP); 2010.

9. OIE. World Assembly of Delegates for Animal Health. Listeria monocytogenes. 2014.

10. Perry L, Heard P, Kane M, Kim H, Savikhin S, DomÍNguez W, et al. Application of multiplex polymerase chain reaction to the detection of pathogens in food. J. Rapid Method Autom. Microbiol. 2007; 15(2):176-98.

11. Jasson V, Jacxsens L, Luning P, Rajkovic A, Uyttendaele M. Alternative microbial methods: An overview and selection criteria. Food Microbiol. 2010;27(6):710-30.

12. Higgins JPT, Green S. Cochrane Handbook for Systematic Reviews of Interventions Version 5.1.0: Cochrane 2011.

13. Liberati A, Altman DG, Tetzlaff J, Mulrow C, Gøtzsche PC, Ioannidis JPA, et al. The PRISMA statement for reporting systematic reviews and metaanalyses of studies that evaluate healthcare interventions: explanation and elaboration. BMJ. 2009;339.

14. Garrido A, Chapela M-J, Román B, Fajardo P, Lago J, Vieites JM, et al. A new multiplex real-time PCR developed method for Salmonella spp. and Listeria monocytogenes detection in food and environmental samples. Food Control. 2013;30(1):76-85.

15. Ruiz-Rueda O, Soler M, Calvó L, García-Gil JL. Multiplex Real-time PCR for the simultaneous detection of Salmonella spp. and Listeria monocytogenes on food samples. Food Anal. Methods. 2011, 4:131-138.

16. Bian X, Jing F, Li G, Fan X, Jia C, Zhou H, et al. A microfluidic droplet digital PCR for simultaneous detection of pathogenic Escherichia coli O157 and Listeria monocytogenes. Biosensors \& bioelectronics. 2015;74:770-7.

17. Stephan R, Schumacher S, Zychowska MA. The VIT technology for rapid detection of Listeria monocytogenes and other Listeria spp. International journal of food microbiology. 2003;89(2-3):287-90.

18. Tang MJ, Zhou S, Zhang XY, Pu JH, Ge QL, Tang XJ, et al. Rapid and sensitive detection of Listeria monocytogenes by loop-mediated isothermal amplification. Current microbiology. 2011;63(6):511-6.

19. Glaser P, Frangeul L, Buchrieser C, Rusniok C, Amend A, Baquero F, et al. Comparative genomics of Listeria species. Science (New York, NY). 2001;294(5543):849-52.

20. Kawasaki S, Fratamico PM, Horikoshi N, Okada Y, Takeshita K, Sameshima T, et al. Evaluation of a multiplex PCR system for simultaneous detection of Salmonella spp., Listeria monocytogenes, and Escherichia coli O157:H7 in foods and in food subjected to freezing. Foodborne pathogens and disease. 2009;6(1):81-9.

21. O'Grady J, Sedano-balbas S, Maher M, Smith T, Barry T. Rapid real-time PCR detection of Listeria monocytogenes in enriched food samples based on the ssrA gene, a novel diagnostic target. Food microbiology. 2008; 25(1):75-84.

22. Schoder D, Schmalwieser A, Schauberger G, Kuhn M, Hoorfar J, Wagner M. Physical characteristics of six new thermocyclers. Clinical chemistry. 2003;49(6 Pt 1):960-3.

23. Cloke J, Arizanova J, Crabtree D, Simpson H, Evans K, Vaahtoranta L, et al. Validation of the Applied Biosystems 7500 Fast Instrument for Detection of Listeria monocytogenes with the SureTect Listeria monocytogenes PCR Assay. Journal of AOAC International. 2016;99(3):676-85.

24. Badosa E, Chico N, Pla M, Pares D, Montesinos E. Evaluation of ISO enrichment real-time PCR methods with internal amplification control for detection of Listeria monocytogenes and Salmonella enterica in fresh fruit and vegetables. Letters in applied microbiology. 2009;49(1):105-11.

25. Wan J, King K, Forsyth S, Coventry MJ. Detection of Listeria monocytogenes in salmon using the Probelia polymerase chain reaction system. Journal of food protection. 2003;66(3):436-40.

26. Jadhav S, Sevior D, Bhave M, Palombo EA. Detection of Listeria monocytogenes from selective enrichment broth using MALDI-TOF Mass Spectrometry. Journal of proteomics. 2014;97:100-6.

27. Kim KP, Singh AK, Bai X, Leprun L, Bhunia AK. Novel PCR Assays Complement Laser Biosensor-Based Method and Facilitate Listeria Species Detection from Food. Sensors (Basel, Switzerland). 2015;15(9):22672-91.

28. Li X, Lv P, Wang L, Guo A, Ma M, Qi X. Application of high resolution pyrolysis gas chromatography/mass spectrometry (HRPGC/MS) for detecting Listeria monocytogenes. Journal of chromatography B, Analytical technologies in the biomedical and life sciences. 2014;971:107-11. 